\title{
Inhibitory Effect of Zirconium Coating to Bone Bonding of Titanium Implants in Rat Femur
}

\author{
Ryohei Takada ${ }^{1, * 1}$, Tetsuya Jinno ${ }^{1}$, Yusuke Tsutsumi ${ }^{2,3,{ }^{* 2}}$, Hisashi Doi ${ }^{2}$, Takao Hanawa ${ }^{2}$ \\ and Atsushi Okawa ${ }^{1}$ \\ ${ }^{1}$ Graduate School of Medical and Dental Sciences, Tokyo Medical and Dental University, Tokyo 113-8510, Japan \\ ${ }^{2}$ Institute of Biomaterials and Bioengineering, Tokyo Medical and Dental University, Tokyo 101-0062, Japan \\ ${ }^{3}$ Graduate School of Engineering, The University of Tokyo, Tokyo 113-8656, Japan
}

\begin{abstract}
When titanium (Ti) alloys are used for bone fixators after bone fracture, Ti alloys form new bone around themselves in human bone. This ability can cause re-fracture when the fixators are retrieved after bone healing. Surface treatments that do not cause bone formation around $\mathrm{Ti}$ alloy are necessary. The purpose of this study was to clarify the inhibitory effect of zirconium ( $\mathrm{Zr}$ ) coating on bone bonding of Ti alloy in rat femur. Non-coated and Zr-coated Ti implants were inserted into the medullary canal of the right and left femur (randomized to side). Four weeks later, the femurs with the implants were removed. The shear strength of implant fixation with the bone was measured by a pull-out test. The amount of the residual new bone adhered on the implants after the pull-out test was evaluated. Pull-out shear strength and the amount of bone elements around implant were lower in $\mathrm{Zr}$-coated group than in non-coated group. Our study indicates that $\mathrm{Zr}$ coating inhibits bone bonding between Ti implant and bone in vivo. This technique may be useful to prevent re-fracture when Ti implants are removed from human bone after bone healing. [doi:10.2320/matertrans.M2016293]
\end{abstract}

(Received August 24, 2016; Accepted October 14, 2016; Published December 9, 2016)

Keywords: surface treatment, pull-out test, osseointegration, zirconium, fracture, orthopaedic surgery

\section{Introduction}

Titanium (Ti) and Ti alloys are widely used for orthopaedic and dental implants, because they show good corrosion resistance and great specific strength. When Ti alloy is surgically implanted into the human bone, calcium phosphate layer spontaneously forms on its surface ${ }^{1-5)}$. This ability of Ti alloy to form calcium phosphate is one of the reasons for its better hard-tissue compatibility than those of other metals and accelerates bone formation around itself in the human bone. However, this ability can cause critical complications when they removed from human bone. When Ti alloys are used for bone fixators such as bone screws and intramedullary nails, Ti alloys form new bone on them and sometimes assimilate with original bone (osseointegration $)^{6-8)}$. Therefore, bone may be re-fractured when the fixators are retrieved after bone healing ${ }^{9-13)}$. Patients suffered re-fracture must be re-treated with some difficulty that did not exist at the first treatment. Although stainless steel which does not equal to Ti alloy in corrosion resistance and strength may have been used to avoid this problem, re-fracture during the removal of stainless steel rod also has been reported ${ }^{14}$. Therefore, surface treatments that do not cause bone formation are necessary for the safe utilization of Ti alloy. However, most of surface treatment techniques studied in the field of biomaterials have targeted bone formation around $\mathrm{Ti}$ alloy ${ }^{6-8,15-17)}$. Surface treatment techniques to inhibit bone formation around $\mathrm{Ti}$ alloy have never been studied.

In this point of view, we have investigated the specificity of zirconium $(\mathrm{Zr})$ which has already been used as a component element in orthopaedic implants because of their strength, high corrosion resistance, low cytotoxicity and low magnetic susceptibility ${ }^{18-22)}$. We previously reported that $\mathrm{Zr}$ inhibits

\footnotetext{
${ }^{* 1}$ Graduate Student, Tokyo Medical and Dental University

${ }^{* 2}$ Corresponding author, E-mail: tsutsumi.met@tmd.ac.jp
}

bone formation around itself because zirconium phosphate is spontaneously formed on $\mathrm{Zr}$ alloy ${ }^{18,20,21)}$. Zirconium phosphate is highly stable and protective and inhibits the formation of calcium phosphate which accelerates bone formation around itself. Moreover, we reported previously that the coating of thin $\mathrm{Zr}$ layer on Ti alloy inhibits the formation of calcium phosphate during immersion in a simulated body fluid ${ }^{19)}$. Thus, $\mathrm{Zr}$ coating on $\mathrm{Ti}$ alloy is expected to be a reasonable and safe way to inhibit the bone bonding without losing the excellent mechanical properties of Ti alloy. However, it is unclear that $\mathrm{Zr}$ coating on Ti alloy can actually inhibit bone bonding in vivo. The purpose of this study was to clarify the inhibitory effect of $\mathrm{Zr}$ coating on bone bonding of Ti alloy in rat femur.

\section{Materials and Methods}

All animal experiments were performed following the approval of the Animal Study Committee of Tokyo Medical and Dental University and conformed to relevant guidelines and laws.

\subsection{Implant preparation \& evaluation}

Ti-6Al-4V alloy rods, $1.4 \mathrm{~mm}$ in diameter and $15 \mathrm{~mm}$ in length, were manufactured. The implants had a distal hole for a pull-out test. The nominal composition of the Ti alloy is shown in Table 1. All implants were blasted with zirconia ( $\mathrm{ZrO}_{2}$ ) particles (TZ-B90, 75-106 $\mu \mathrm{m}$, Tosoh Corp., Japan) to a mat-like surface. After blasting, samples were divided into two groups based on whether they were $\mathrm{Zr}$-coated or not (Control).

\subsection{Zr coating}

Before the coating process of $\mathrm{Zr}$, plasma cleaning of implant surface was performed to remove contamination layer and enhance adherence of the coating layer (YHS-R, SAKI- 
Table 1 The nominal composition of Ti-6Al-4V.

\begin{tabular}{cc}
\hline Element & mass\% \\
\hline $\mathrm{Fe}$ & $<0.30$ \\
$\mathrm{O}$ & $<0.20$ \\
$\mathrm{~N}$ & $<0.05$ \\
$\mathrm{H}$ & $<0.015$ \\
$\mathrm{Al}$ & $5.5-6.75$ \\
$\mathrm{~V}$ & $3.5-4.5$ \\
$\mathrm{Ti}$ & Balance \\
\hline
\end{tabular}

GAKE-Semiconductor Co. Ltd., Japan). For the preparation of $\mathrm{Zr}$-coated implants, sputter-deposition was performed in this study. The implants after the blasting were attached onto the rotating holder as an anode in a RF magnetron sputter deposition instrument (Canon ANELVA, Japan). A pure $\mathrm{Zr}$ target (Furuuchi Chemical, Japan) was used as a cathode. The sputter deposition was carried out with the following conditions: $50 \mathrm{~W}$ of the applied voltage, $150 \mathrm{~mm}$ of the target-substrate distance, and 21 minutes of the deposition time. In our preliminary experiments ${ }^{19)}$, a calibration curve was obtained from both the thickness of sputter-deposited layer determined by a laser microscope and deposition time. The thickness of the $\mathrm{Zr}$ layer was adjusted to be $200 \mathrm{~nm}$ by using the calibration curve.

Surface roughness of samples before implantation was observed by three-dimensional laser microscope (LEXT OLS4000, Olympus Co., Ltd., Japan) to determine difference of surface roughness between control and $\mathrm{Zr}$-coated group. $\mathrm{X}$-ray fluorescence spectrometer (XRF, XGT-1000WR, HORIBA, Ltd., Japan) was used to confirm the presence of the $\mathrm{Zr}$ coating layer. Quantitative analyses of XRF results were performed using the fundamental parameter method without standard samples.

\subsection{Implantation}

Five 11-week-old male Sprague-Dawley rats (Sankyo Laboratory Service, Tokyo, Japan) weighing 300-350 g were used. The rats were housed in cages and were given free access to food and water. The rats were anaesthetized with intraperitoneal injections of chloral hydrate. The surgery was performed under aseptic conditions. After shaving and scrubbing with alcohol, each knee was incised on the medial side of patellar tendon to expose the joint surface. Control and Zr-coated implants sterilized in an autoclave were inserted into the medullary canal of the right and left femur (Fig. 1), after reaming the intercondylar notch of each distal femur with a $1.1 \mathrm{~mm}$ drill. Control and $\mathrm{Zr}$-coated implants were randomized to one or the other side. Each animal therefore acted as its own control. Four weeks later, all the rats were sacrificed and the femurs with the implants were removed.

\subsection{Biomechanical analysis}

The shear strength of implant fixation with the bone was measured by a pull-out test. The distal bone and soft tissue around the rod-hole was carefully removed. A $0.3 \mathrm{~mm}$ in diameter polyethylene line (ULTRA CAST MAN wX8 Polyethylene second ver., YGK Yoz-Ami, Osaka, Japan) was passed through the exposed rod-hole. Proximal bone was

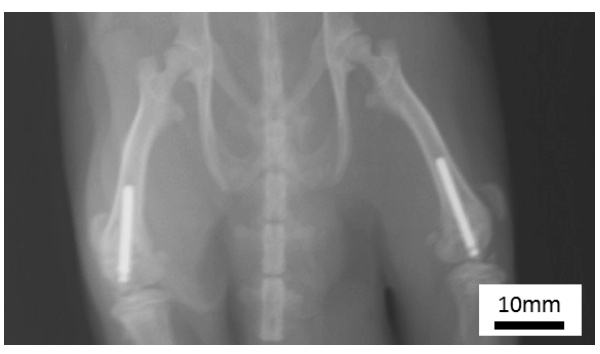

Fig. 1 A radiograph of the femora of a rat.

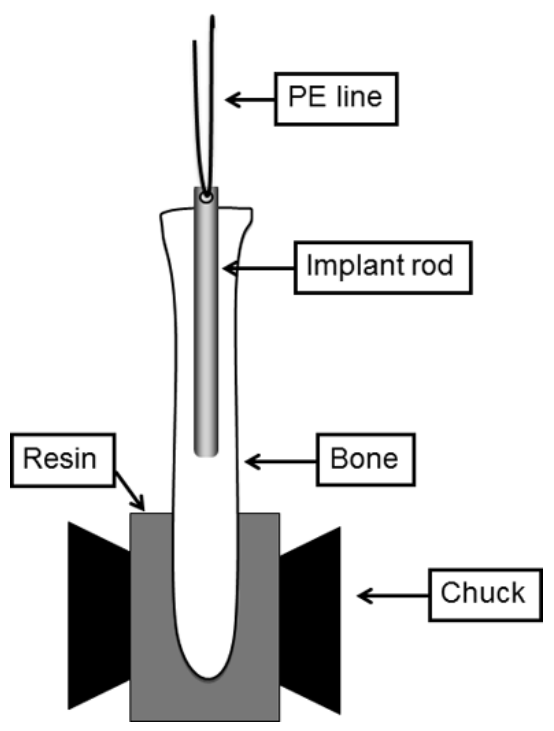

Fig. 2 A schematic of the apparatus for the pull-out test.

fixed by acrylic resin (Durocit, Marumoto Struers K.K., Tokyo, Japan) for combining with the tensile-testing machine (AG-IS 500N; Shimadzu Corp., Japan). The polyethylene line was gripped with an implant in the direction of the applied force (Fig. 2). A pull-out test was conducted at a crosshead speed of $0.1 \mathrm{~mm} / \mathrm{min}$ to removal. The maximum shear strength of the bone-implant interface $(\mathrm{MPa})$ was determined by dividing the force at the point of failure by the surface area (without base area) of the implant.

\subsection{Surface observation and analysis}

After the pull-out test, accretions around the implants, which were considered to be derived from new bone, were observed by a optical microscope (SZX12, Olympus Co., Ltd, Japan). Additionally, a scanning electron microscope (SEM, S-3400N, Hitachi High-Technologies Corp, Japan) was used for microscopic observations.

\subsection{Elementary analysis}

Before and after the pull-out test, XRF was used to confirm the presence of the $\mathrm{Zr}$ coating layer without peeling-off even after the pull-out test.

The amount of the residual new bone adhered on the implants after the pull-out test was evaluated by the following method. A reagent-grade nitric acid (60-61\%) and ultra-pure water were mixed with a volume ratio of 1:99. The implants after the pull-out test were immersed and well-stirred in the 
nitric acid solution by ultrasonic cleaning machine to completely dissolve the precipitates including the new bone formed during the implantation. Inductively-coupled plasma atomic spectroscopy (ICP-AES, ICPS-7000, Shimadzu Corp., Japan) was used to determine the concentrations of calcium, phosphate, and magnesium ions which were included in the new bone dissolved into the nitric acid solution. Prior to the measurement, standard solutions including each element with concentrations of $0.01,0.1$, and $1 \mathrm{ppm}$ were also prepared from the reagent-grade chemicals for chemical analysis (Kanto Chemical Co. Inc., Japan) to obtain the calibration lines. The amounts of calcium, magnesium, and phosphorous were calculated from the results.

\subsection{Statistical analysis}

Biomechanical data were analyzed by paired-t-test to determine difference of shear strength between control and $\mathrm{Zr}$-coated group. The results of ICP-AES analysis were also analyzed by paired-t-test to determine difference of the concentrations of ions between the two groups. The results were considered significant, if $p<0.05$.

\section{Results}

\subsection{Implant evaluation}

Three-dimensional laser micrographs are shown in Fig. 3. The surface roughness $\left(R_{\mathrm{a}}\right)$ of control and $\mathrm{Zr}$-coated groups were $0.50 \pm 0.08 \mu \mathrm{m}$ and $0.51 \pm 0.05 \mu \mathrm{m}$, respectively (mean $\pm \mathrm{SD}, p=0.33$ )

\subsection{Biomechanical analysis}

Ten femora from 5 rats were analyzed. The result of a load-displacement curve of a $\mathrm{Zr}$-coated case as a typical example was shown in Fig. 4. The curves resulting from elasticity of polyethylene line were observed before the point of maximum force in all cases. The maximum force was recorded at the point of failure of bone-implant fixation. In all rats, pull-out shear strength of $\mathrm{Zr}$-coated rod was lower than control one (Fig. 5). Pull-out shear strength was significantly lower in $\mathrm{Zr}$-coated group $(0.09 \pm 0.03 \mathrm{MPa})$ than in control group $(0.15 \pm 0.05 \mathrm{MPa})($ mean $\pm \mathrm{SD}, p=0.03)$.

\subsection{Surface observation and analysis}

In the analysis of optical micrographs, accretions around implants, which were considered to be derived from new bone, were apparently observed more in control group than in

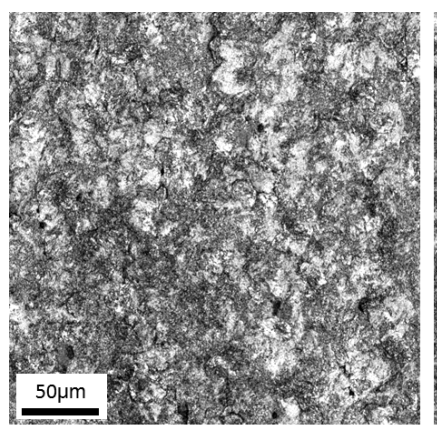

Control

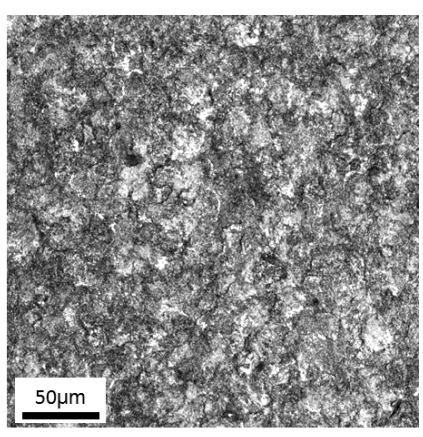

Zr-coated
Fig. 3 Laser micrographs of control and $\mathrm{Zr}$-coated group.
Zr-coated group (Fig. 6).

The results of SEM analysis were shown in Fig. 7. There was almost no difference between both the groups in the high-magnification images. However, the amount of the accretion which was observed as brighter part in backscattered-electron image, meaning lighter element than $\mathrm{Ti}$, showed apparently different. The large particles of the accretion were observed only on the implants without $\mathrm{Zr}$ coating, as also shown in the optical micrographs.

\subsection{Elementary analysis}

The peaks derived from $\mathrm{Zr}$ in XRF spectra were observed on both $\mathrm{Zr}$-coated implant surfaces before and after the pull-

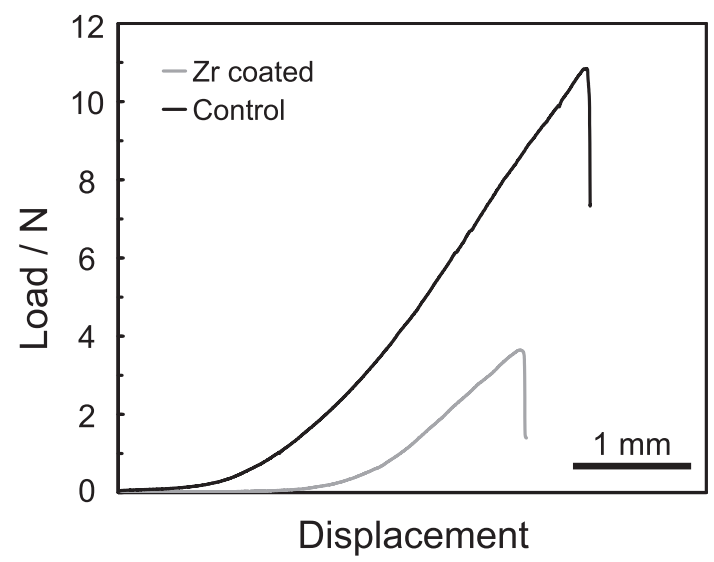

Fig. 4 Example of the results of pull-out test on control and $\mathrm{Zr}$-coated specimens implanted in the same rat (Rat number 1).

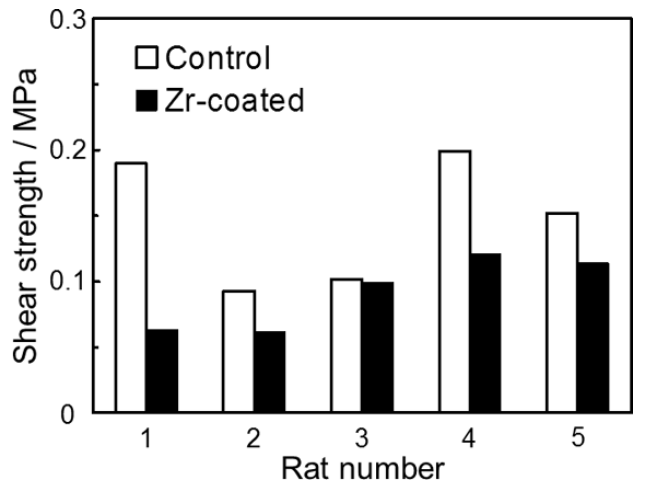

Fig. 5 Results of pull-out test on control and Zr-coated group.

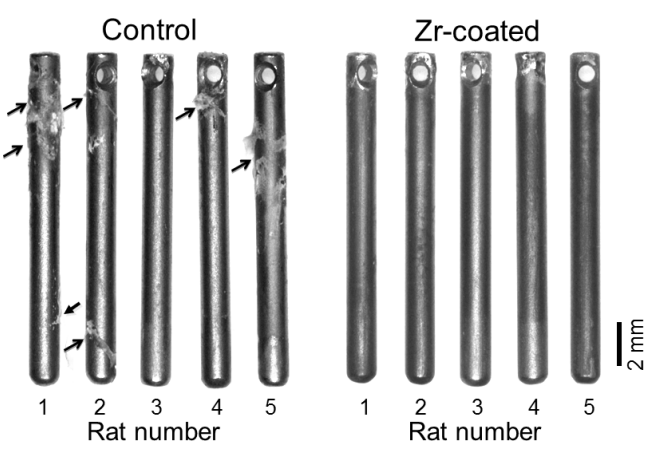

Fig. 6 Optical micrographs of the implants after pull-out test. 


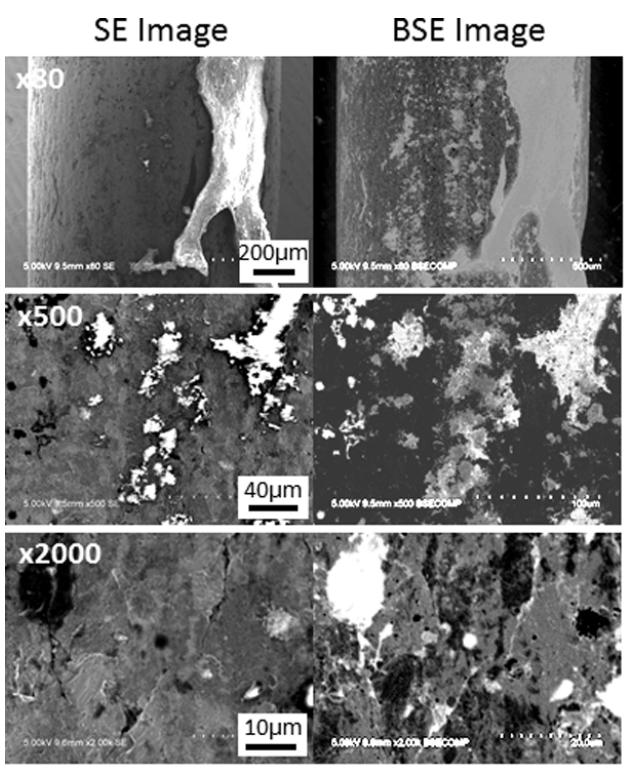

control

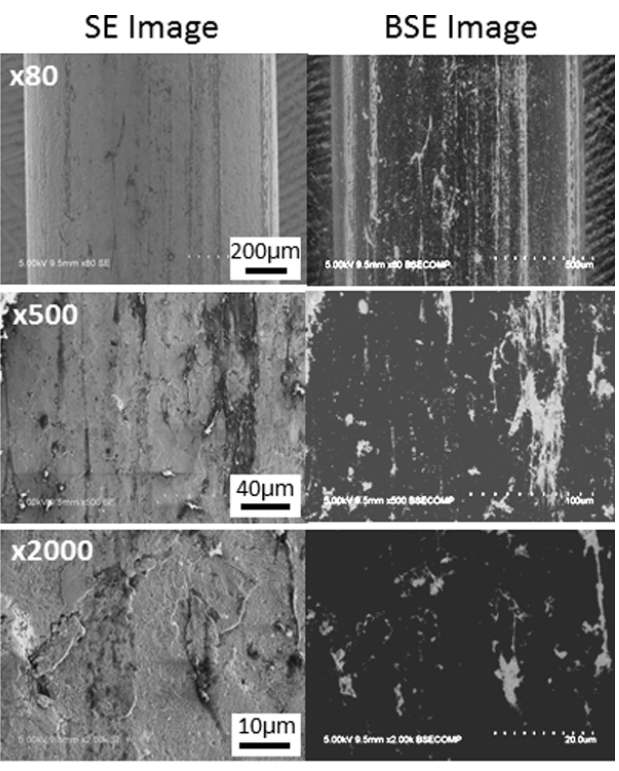

Zr-coated

Fig. 7 Scanning electron micrographs of the implants after pull-out test.

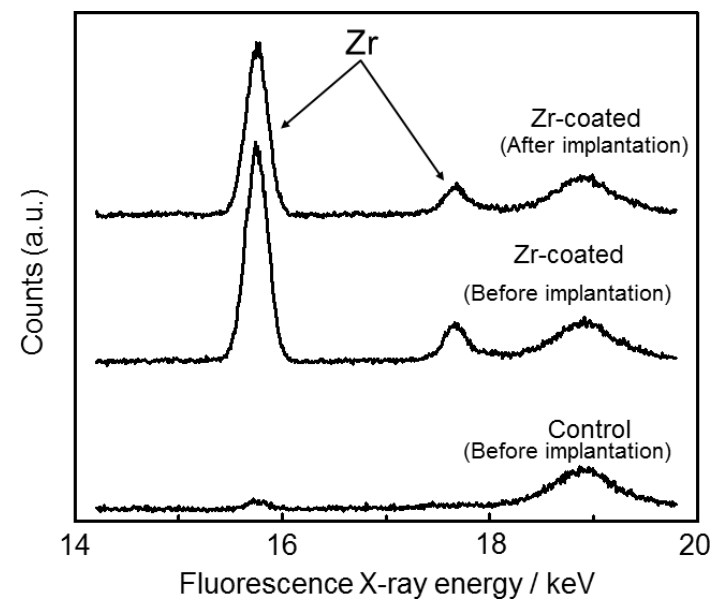

Fig. 8 XRF spectra around the $\mathrm{Zr} \mathrm{K} \alpha$ and $\mathrm{K} \beta$ energy region.

out test (Fig. 8). ICP-AES analysis found that all concentrations of calcium, phosphate, and magnesium ions were greater in control group than in $\mathrm{Zr}$-coated group with marginal significance $(0.05<p<0.1)$ (Fig. 9). There was significant correlation between concentration of calcium, phosphate, and magnesium ions and pull-out shear strength in both groups $(0.77<r<0.82, p<0.001$ for all $)$.

\section{Discussion}

In this study, pull-out shear strength was significantly lower in $\mathrm{Zr}$-coated group than in control group. Moreover, there was significant correlation between pull-out shear strength and amounts of bone elements in ICP-AES analysis. On the other hand, there was no significant difference of surface roughness of the rod between control and $\mathrm{Zr}$-coated group. The presence of $\mathrm{Zr}$ was confirmed on the $\mathrm{Zr}$-coated implant surfaces both before and after the pull-out test. Thus, Zr coating did not affect the surface roughness and $\mathrm{Zr}$ coating layer had enough durability not to be peeled off from implant surface. These results indicate that $\mathrm{Zr}$ coating influenced osseointegration around the Ti alloy and inhibited bone bonding between implant and bone in rat femur.

When Ti alloys is immersed in simulated body fluids containing both calcium and phosphate ions, calcium phosphate spontaneously forms on the material surface ${ }^{3-5)}$. It is considered that this ability of Ti alloy to form calcium phosphate layer accelerates bone formation around itself in the human bone ${ }^{17,20)}$. On the other hand, calcium phosphate is never incorporated on surface of $\mathrm{Zr}$ alloy, while zirconium phosphate, which is preferentially formed on $\mathrm{Zr}$, is highly stable and protective. When $\mathrm{Zr}$ was added to Ti alloy as an alloying element, the ability of Ti alloy to form calcium phosphate was weakened, and only phosphate without calcium was formed on $\mathrm{Ti}-\mathrm{Zr}$ alloys that contained more than 50 mass $\% \mathrm{Zr}^{21}$. Moreover, the coating of thin $\mathrm{Zr}$ layer on Ti alloy inhibits the formation of calcium phosphate during immersion in a simulated body fluid in our previous study ${ }^{19}$. Therefore, it is considered that the formation of zirconium phosphate around implant inhibited bone bonding between implant and bone in Zr-coated group.

This is the first study to demonstrate inhibitory effect of $\mathrm{Zr}$ coating to bone bonding of a Ti alloy in vivo. Although the number of samples was relatively small, certain inhibitory effect of $\mathrm{Zr}$ coating to bone bonding was confirmed.

There are several limitations in this study. First, in animal experimentation, although control and Zr-coated implants were randomized to one or the other side, investigators were not blinded to implant choice. Secondly, histological examination was not performed. The details of new bone formation around implant in vivo were not clarified. There has been no histological study about Zr-coated Ti alloy. However, according to histological examination in a previous study comparing osteoconduction between solid $\mathrm{Zr}$ and $\mathrm{Ti}^{23)}$, lower bone-implant contact area was observed around $\mathrm{Zr}$ compared to $\mathrm{Ti}$ after implantation in rat femurs. It is considered that the same 


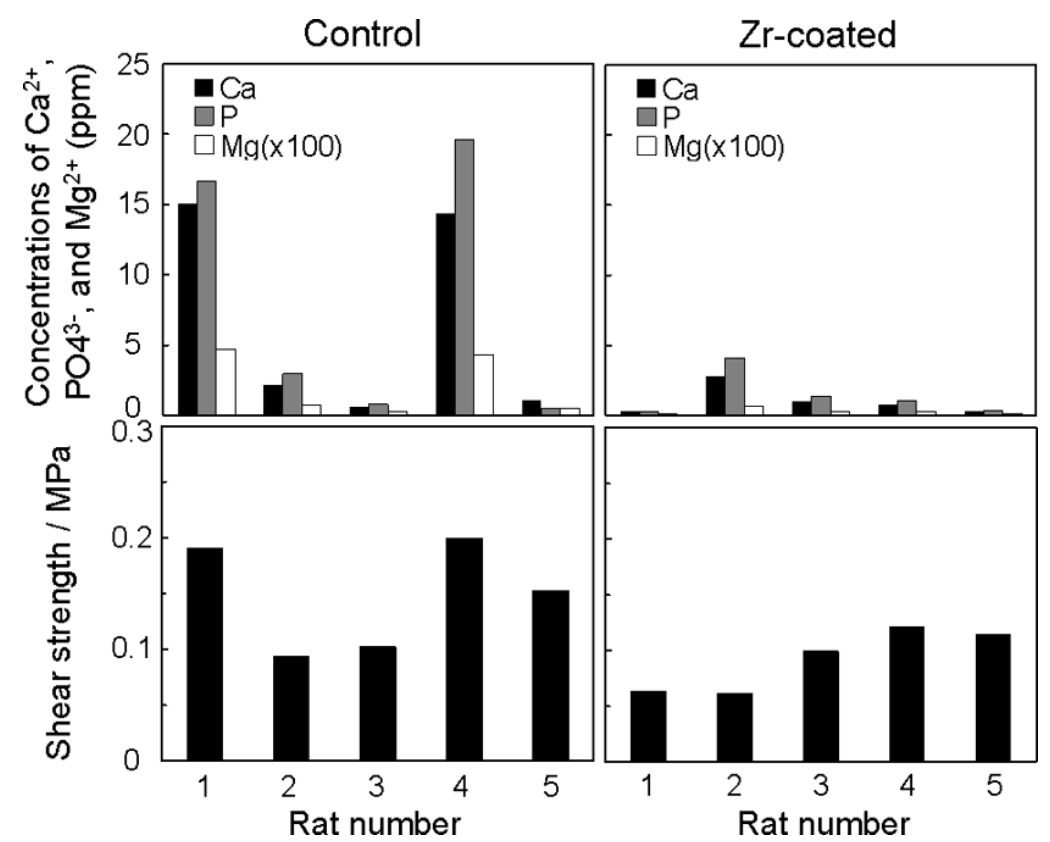

Fig. 9 Results of ICP-AES measurement in comparison with the shear strength by the pull-out test.

phenomenon around $\mathrm{Zr}$-coated Ti alloy should have been occurred in our study. Thirdly, our results had a large individual difference. As a reason for that, it is considered that each of the rats had a different size of femoral medullary space nevertheless we used the rats in the same age range. To minimize the effects of individual difference, we used bilateral comparison model.

This technique is considered to be useful for prevention of re-fracture after orthopaedic implantation. Moreover, we may be able to apply this technique to orthopaedic arthroplasty. $\mathrm{Zr}$ coating to the area of the implant not expected to bone bonding may be useful for prevention of stress shielding after implantation; bone bonding on desired part of the implant may be accelerated ${ }^{24)}$.

\section{Conclusion}

Inhibitory effect of $\mathrm{Zr}$ coating on $\mathrm{Ti}$ alloy to bone bonding was evaluated by pull-out test in vivo. Our study indicates that $\mathrm{Zr}$ coating inhibits bone bonding with implanted $\mathrm{Ti}$ alloy. This technique may be useful to prevent the complications after implantation due to excessive bonding of Ti implants to surrounding bone, without losing any excellent mechanical properties.

\section{Acknowledgement}

This work was supported by JSPS KAKENHI Grant Numbers JP25709064 and JP15H03018.

\section{REFERENCES}

1) M. Niinomi: Sci. Technol. Adv. Mater. 4 (2003) 445-454.

2) M. Esposito, J. Lausmaa, J.M. Hirsch and P. Thomsen: J. Biomed. Ma- ter. Res. 48 (1999) 559-568.

3) T. Hanawa and M. Ota: Biomaterials 12 (1991) 767-774.

4) K.E. Healy and P. Ducheyne: J. Biomed. Mater. Res. 26 (1992) 319338.

5) S. Hiromoto, T. Hanawa and K. Asami: Biomaterials 25 (2004) 979986.

6) T. Jinno, V.M. Goldberg, D. Davy and S. Stevenson: J. Biomed. Mater. Res. 42 (1998) 20-29.

7) J.E. Feighan, V.M. Goldberg, D. Davy, J.A. Parr and S. Stevenson: J. Bone Joint Surg. Am. 77 (1995) 1380-1395.

8) T. Jinno, S.K. Kirk, S. Morita and V.M. Goldberg: J. Arthroplasty 19 (2004) 102-109.

9) M. Takakuwa, M. Funakoshi, K. Ishizaki, T. Aono and H. Hamaguchi: J. Bone Joint Surg. Br. 79 (1997) 444-445.

10) D.H. Jones and G. Schmeling: J. Orthop. Trauma 13 (1999) 271-273.

11) C.J. Seebauer, K.M. van Scherpenzeel, N.P. Haas and H.J. Bail: Arch. Orthop. Trauma Surg. 129 (2009) 949-953.

12) P.L. Sanderson, W. Ryan and P.G. Turner: Injury 23 (1992) 29-30.

13) H. Young and T. Claire: Injury 38 (2007) 223-226.

14) M. Aizawa, T. Jinno, H. Nanke, K. Ishii and S. Kawachi: J Med Cases. 6 (2015) 105-108.

15) T. Hara, K. Hayashi, Y. Nakashima, T. Kanemaru and Y. Iwamoto: J. Bone Joint Surg. Br. 81 (1999) 705-709.

16) J.J. Jaatinen, R.K. Korhonen, A. Pelttari, H.J. Helminen, H. Korhonen, R. Lappalainen, et al.: Acta Orthop. 82 (2011) 499-503.

17) T. Hanawa, Y. Kamiura, S. Yamamoto, T. Kohgo, A. Amemiya, H. Ukai, et al.: J. Biomed. Mater. Res. 36 (1997) 131-136.

18) Y. Tsutsumi, D. Nishimura, H. Doi, N. Nomura and T. Hanawa: Mater. Sci. Eng. C 29 (2009) 1702-1708.

19) E. Kobayashi, M. Ando, Y. Tsutsumi, H. Doi, T. Yoneyama, M. Kobayashi and T. Hanawa: Mater. Trans. 48 (2007) 301-306.

20) T. Hanawa, S. Hiromoto, K. Asami, O. Okuno and K. Asaoka: Mater. Trans. 43 (2002) 3000-3004

21) T. Hanawa, O. Okuno and H. Hamanaka: J. Jpn. Inst. Metals 56 (1992) 1168-1173.

22) A. Yamamoto, R. Honma and M. Sumita: J. Biomed. Mater. Res. 39 (1998) 331-340.

23) H. Matsuno, A. Yokoyama, F. Watari, M. Uo and T. Kawasaki: J JPn Soc Dent Mater. 18 (1999) 447-462.

24) K. Miyatake, T. Jinno, D. Koga, Y. Yamauchi, T. Muneta and A. Okawa: J. Arthroplasty 30 (2015) 2237-2241. 